\title{
Preparation and Properties of Electrically Conductive Polyaniline-Polystyrene Composites by in-situ Polymerization and Blending
}

\author{
Se Young $\mathrm{OH}^{\dagger}{ }^{\dagger}$ Hyung Chul KoH, Jeong Woo CHOI, Hee-Woo RheE, \\ and Hyung Su KIM* \\ Department of Chemical Engineering, Sogang University, Seoul 100-611, Korea \\ * Department of Chemical Engineering, Dankook University, Seoul 140-714, Korea
}

(Received August 9, 1996)

\begin{abstract}
Electrically conductive polyaniline (PANI)-polystyrene (PS) composites were prepared by in-situ polymerization and blending. The polymerization was carried out by adding the oxidant and dodecylbenzenesulfonic acid (DBSA) dissolved in xylene to the xylene solution comprising aniline and PS. The electrical conductivity of PANI-PS composites was improved with increasing amount of PANI and reached a high value of $0.1 \mathrm{~S} \mathrm{~cm}^{-1}$ at content of $12 \mathrm{wt} \%$. The PANI content in PANI-PS composites was calculated by means of elemental analysis and weight measurements. The PANI-PS composites were very soluble in organic solvents such as chloroform, xylene, and $N$-methylpyrrolidone (NMP). The electrical conductivity of PANI, doped with dodecylbenzenesulforic acid (DBSA), and thermally treated at $180^{\circ} \mathrm{C}$ for $3 \mathrm{~h}$ was more stable than that of conventional PANI-HCl complex. The structure and morphology of PANI-PS composites were investigated through the measurements of FT-IR and SEM (scanning electron micrograph).

KEY WORDS Polyaniline-Polystyrene Composite / Electrical Conductivity / Solubility / Therma Stability / Structure /
\end{abstract}

Conducting polymers have attracted considerable attention because of their electrical and optical properties and many potential applications such as energy storage, ${ }^{1}$ electromagnetic interference shielding, ${ }^{2,3}$ optoelectronic device, ${ }^{4,5}$ and sensor, ${ }^{6}$ etc. So far, however, only a few technical applications for this class of compounds have been realized, since organic conductive materials are, in general, very difficult to be processed. Several attempts have been made to improve the processibility of conducting polymers through the use of molecular design, ${ }^{7,8}$ copolymerization, ${ }^{9}$ and functionalized organic dopants. ${ }^{10,11}$ It has been recently reported that polyaniline (PANI) doped with organic protonic acids such as dodecylbenzenesulfonic acid (DBSA) and camphorsulfonic acid (CSA) could be soluble in chloroform, xylene, and $m$-cresol solvents. Thus, PANI composites could be obtained from solution blending in the conducting form. However, this method needs the complicated steps such as chemical polymerization of PANI in $\mathrm{HCl}$ solution, reduction of PANI- $\mathrm{HCl}$ complex in $\mathrm{NaOH}$ solution, redoping of PANI base with organic protonic acids, and solution blending of PANI and matrix polymer in organic solvents. ${ }^{11}$ On the other hand, Ruckenstein et al. reported a route to prepare a PANI-polystyrene (PS) composite by emulsion pathway. ${ }^{12}$ This PANI was doped with $\mathrm{HCl}$ so that it significantly deteriorated at the elevated temperature of more than $150^{\circ} \mathrm{C}$ under nitrogen, which is reported to be mainly due to the elimination of dopant molecule.

In this study, we have developed a simple one-step process to prepare the conductive and thermally stablending. In order to improve the thermal stability of composites, DBSA and DDQ were used as a dopant and an oxidant, respectively. PS was used as a matrix polymer since it is one of the most general purpose polymer. The physical properties, structure, and thermal stability of

$\uparrow$ To whom correspondence should be addressed. the prepared PANI-PS composites were investigated from the measurements of FT-IR, SEM, and TGA.

\section{EXPERIMENTAL}

\section{Materials}

2,3-Dichloro-5,6-dicyano-1,4-benzoquinone (DDQ) and ammoniumpersulfate (APS) used as oxidant were purchased from Aldrich Co. Commercial grade aniline (Aldrich, $95.5 \%$ ) and $p$-xylene were purified by vacuum distillation prior to use. Dodecylbenzenesulfonic acid (DBSA, Janssen Chimica, 97\%), Lewis acid, and organic solvents such as chloroform and $N$-methylpyrrolidone (NMP) were used as-received without further purification. Polystyrene (Aldrich, $M_{w}=80000$ ) was used as a matrix polymer.

\section{Preparation of PANI-PS Composite}

A typical procedure for the preparation of PANI-PS composite was as follows: A $500 \mathrm{ml}$ three-necked round bottom flask equipped with a sealed mechanical stirrer and a dropping funnel was charged with $50 \mathrm{ml}$ of distilled xylene. PS and aniline monomer were added under argon atmosphere. The solution was stirred for $30 \mathrm{~min}$, and the oxidant with DBSA dissolved in xylene was dropped into the flask over a period of $45 \mathrm{~min}$. Polymerization was conducted at $25^{\circ} \mathrm{C}$ for $21 \mathrm{~h}$. The reaction was terminated by pouring the polymerization solution into a large amount of methanol. The PANI-PS composite was filtered off and washed with methanol and water, and then dried under vacuum at $45^{\circ} \mathrm{C}$ for $24 \mathrm{~h}$.

\section{Measurements}

Electrical conductivity of the PANI-PS composite was measured by using 4-probe method. PANI content of the composite was calculated through weight uptake and elemental analysis. FT-IR spectra were obtained by a Perkin-Elmer 2000 FT-IR spectrometer using $\mathrm{KBr}$ 
method. Morphology of the PANI-PS composite was observed by a Hitachi scanning electron micrograph (SEM)-2500. Thermal analysis was carried out in a Dupont 9900 thermogravimetric analyzer 951 under nitrogen atmosphere and at a heating rate of $20^{\circ} \mathrm{C} \mathrm{min}^{-1}$.

\section{RESULTS AND DISCUSSION}

PANI-PS composites were obtained by polymerizing aniline with a APS or DDQ solution containing DBSA as a dopant in the PS dissolved xylene solution. The yield, PANI-DBSA complex weight fractions, and electrical conductivity of the PANI-PS composites prepared at various ratios of aniline and PS are shown in Table I. The yield of PANI-DBSA complex prepared by an APS oxidant appeared to be in the range of $24-32 \%$ at aniline and oxidant mole ratio of 2.2 , and it is increased as the concentration of oxidant is increased as shown in the run No. 10. Since no methanolsoluble product was checked in the present study, the yield was based only on the methanol insoluble products. As presented in Table I, PANI-DBSA content in the composite is mainly influenced by aniline/PS or aniline/oxidant ratio. The electrical conductivity of the composite is increased as the conductive component is increased, and its value was $15-18$ orders of magnitude higher than that of PS. Figure 1 shows the change in electrical conductivity as a function of the weight fraction of PANI in the composite. It is important to note that the high level of electrical conductivity around $0.1 \mathrm{~S} \mathrm{~cm}^{-1}$ can be achieved in a PANI-PS composite containing only $12 \mathrm{wt} \%$ of the conductive component, which represents the indication of a typical percolation threshold. ${ }^{13}$ It is evident from the Figure 1 that the critical weight fraction is in the range of $6-10 \mathrm{wt} \%$, which is much lower than that of about $25 \mathrm{vol} \%$ observed for the polypyrrole-polymer composite. ${ }^{14}$ But, much smaller percolation thresholds have been reported recently, for example, $c a .2 \mathrm{wt} \%$ reported by Cao et al. ${ }^{11}$ and 0.003 volume fraction by PANI-CSA blended in PMMA reported by Yoon et al. ${ }^{15}$ The value of critical weight fraction in the conductive polymer composites is mainly influenced by morphology and domain size or distribu- tion of dispersed conductive component. The threshold value in polypyrrole-polymer composites is close to standard threshold value. This is common in carbon black filled conductive composites, where carbon black has aggregated structure. According to Cao's TEM micrographs on PANI-CSA composites, PANI formed the stringy interconnected network structure, which resulted in very low percolation threshold value. ${ }^{16}$ When PANI was doped with DBSA, the percolation threshold in PANI composite was about $10 \mathrm{wt} \%,{ }^{11}$ which is closed to our present sample. This result may indicate that the type of protonic acid affect the morphology in the composite. In the case of PANI-PS composites prepared by a DDQ oxidant (run No. 3, 5, 7, 12), the electrical conductivity as a function of PANI-DBSA content was inferior to that prepared by an APS oxidant, because pure PANI prepared by a DDQ oxidant had a low conductivity of $0.16 \mathrm{~S} \mathrm{~cm}^{-1}$. It may be considered that the low conductivity is, in part, due to a short conjugation length of PANI backbone. Table II summarizes the result of elemental analysis and solubility of PANI-PS composites. Since PS does not contain nitrogen, the PANI content in the composite can be calculated from

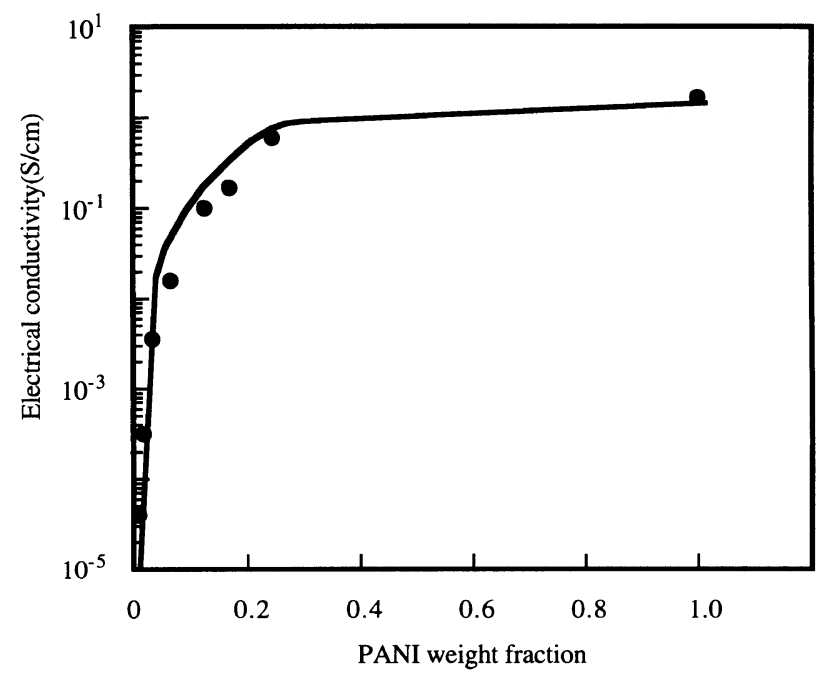

Figure 1. Electrical conductivity of PANI-PS composites as a function of PANI weight fraction.

Table I. Yield, PANI-DBSA weight fractions, electrical conductivity of the PANI-PS composites prepared at various weight ratios of PS to aniline

\begin{tabular}{|c|c|c|c|c|c|}
\hline \multirow{2}{*}{$\begin{array}{l}\text { Run } \\
\text { No. }\end{array}$} & \multirow{2}{*}{ PS/aniline ${ }^{\mathbf{a}}$} & \multirow{2}{*}{$\begin{array}{c}\text { Yield of composite } \\
\%\end{array}$} & \multirow{2}{*}{$\begin{array}{c}\text { Yield of PANI-DBSA } \\
\% \frac{1}{0}\end{array}$} & \multirow{2}{*}{$\frac{\text { PANI-DBSA content }^{\mathrm{b}}}{\mathrm{wt} \%}$} & \multirow{2}{*}{$\frac{\text { Electrical conductivity }}{\mathrm{S} \mathrm{cm}^{-1}}$} \\
\hline & & & & & \\
\hline 1 & $20 / 1$ & 97.6 & 28.6 & 0.014 & 0.00004 \\
\hline 2 & $10 / 1$ & 93.2 & 26.0 & 0.024 & 0.00032 \\
\hline 3 & $20 / 1^{c}$ & 99.0 & 80.0 & 0.038 & 0.00045 \\
\hline 4 & $5 / 1$ & 87.3 & 25.5 & 0.047 & 0.0035 \\
\hline 6 & $3 / 1$ & 82.8 & 31.2 & 0.094 & 0.016 \\
\hline 7 & $2 / 1^{c}$ & 96.7 & 90.2 & 0.240 & 0.053 \\
\hline 8 & $1.5 / 1$ & 73.0 & 32.0 & 0.176 & 0.1 \\
\hline 9 & $1 / 1$ & 66.0 & 31.5 & 0.244 & 0.17 \\
\hline 10 & $1 / 1^{d}$ & 77.0 & 53.8 & 0.351 & 0.6 \\
\hline 11 & $0 / 1$ & & 23.8 & 1.000 & 1.7 \\
\hline 12 & $0 / 1^{c}$ & & 86.3 & 1.000 & 0.16 \\
\hline
\end{tabular}

Polymerized for $21 \mathrm{~h}$ at room temperature. [aniline]/[ammoniumpersulfate] $=2.2$ [aniline]/[DBSA] $=1$. a Weight ratio of PS to aniline. b PANI-DBSA weight fractions were calculated by weight measurement. $\quad{ }^{\mathrm{c}}[$ aniline $] /[\mathrm{DDQ}]=1$. $^{\mathrm{d}}[$ aniline $] /[$ ammoniumpersulfate $]=$ 1.4 . 
Table II. Elemental analysis and solubility of the PANI-PS composites

\begin{tabular}{|c|c|c|c|c|c|c|c|}
\hline \multirow{2}{*}{ Run No. } & \multirow{2}{*}{$\begin{array}{l}\mathrm{C} \\
\%\end{array}$} & \multirow{2}{*}{$\begin{array}{l}\mathrm{H} \\
\%\end{array}$} & \multirow{2}{*}{$\begin{array}{l}\mathrm{N} \\
\%\end{array}$} & \multicolumn{3}{|c|}{ Solubility } & \multirow{2}{*}{$\begin{array}{c}\text { PANI-DBSA content } \\
\mathrm{wt} \%\end{array}$} \\
\hline & & & & Chloroform & Xylene & NMP & \\
\hline 1 & 91.9 & 8.22 & $<0.3$ & $\odot$ & ○ & ○ & (1.4) \\
\hline 2 & 89.7 & 7.25 & 0.36 & () & () & () & (2.4) \\
\hline 3 & $\mathrm{C}^{\mathrm{a}}$ & - $^{a}$ & - $^{a}$ & () & () & () & (3.8) \\
\hline 4 & 88.5 & 6.98 & 0.57 & 0 & 0 & 0 & (4.7) \\
\hline 5 & 87.2 & 6.39 & 1.17 & 0 & 0 & 0 & $11.4 \quad(10.9)$ \\
\hline 6 & 87.8 & 6.69 & 0.98 & 0 & 0 & 0 & $10.26 \quad(9.4)$ \\
\hline 7 & 82.7 & 6.12 & 2.70 & 0 & 0 & 0 & $24.6 \quad(24.0)$ \\
\hline 8 & $-^{a}$ & - $^{a}$ & - & $\triangle$ & $x$ & $\triangle$ & - ${ }^{\mathrm{a}} \quad(17.6)$ \\
\hline 9 & 82.5 & 6.22 & 2.35 & $x$ & $x$ & $\triangle$ & $24.6 \quad(24.4)$ \\
\hline 10 & $-^{a}$ & - $^{a}$ & - $^{\mathrm{a}}$ & $x$ & $x$ & $\triangle$ & - $^{\mathrm{a}} \quad(35.1)$ \\
\hline 11 & 55.4 & 5.03 & 9.55 & $x$ & $x$ & $\triangle$ & \\
\hline 12 & 62.4 & 5.51 & 10.26 & $x$ & $x$ & $\triangle$ & \\
\hline
\end{tabular}

PANI-DBSA contents were calculated by elemental analysis. ${ }^{a}$ No measurement. $\odot$, very soluble; $O$, soluble; $\triangle$, slightly soluble; $\times$, insoluble. A parenthesis represented PANI-DBSA content by weight measurement.

the elemental analysis of nitrogen by comparing to the nitrogen content of the pure PANI. This value was almost consistent with that obtained from the weight measurement.

It has been reported that the conducting polymers consisting of conjugated double bond are insoluble in common organic solvents and infusible owing to the strong van der Waals interactions between $\pi$ electrons of polymer chains. ${ }^{17}$ However, PANI doped with a properly functionalized organic protonic acid can be soluble because of the reduced interactions between polymer chains. The PANI-PS composite containing the PANI-DBSA complex of $1-4 \mathrm{wt} \%$ was highly soluble in the common organic solvents such as chloroform, xylene, and NMP as shown in Table II. The solubility, however, decreased with increasing the conductive component. The decrease in solubility along with the increased PANI content can be attributed to the partial doping by a strong acid of $\mathrm{H}_{2} \mathrm{SO}_{4}$ compared to the organic protonic acid, because an APS oxidant gives rise to $\mathrm{H}_{2} \mathrm{SO}_{4}$ in situ aniline oxidation. Thus, we next try to polymerize with DDQ oxidant that does not yield an $\mathrm{H}_{2} \mathrm{SO}_{4}$ as a by product during the aniline polymerization. Hence, the prepared PANI-PS composite containing conductive component of $24 \mathrm{wt} \%$ was soluble in chloroform. Here it should be noted that the DDQ is the most promising catalyst among the oxidants for the polymerization of aniline, judging from the solubility of the composite.

The SEM micrographs of PANI-PS composites (run No. 3, 5, 7) as a function of PANI-DBSA content are presented in Figure 2. The PS sample precipitated by pouring a PS solution dissolved in xylene into a large amount of methanol showed fibril structure. This morphology can also be observed in the PANI-PS composite containing a small amount of PANI-DBSA complex $(3.8 \mathrm{wt} \%)$, but was no longer seen as the amount of conductive component increases. The composite containing $24 \mathrm{wt} \%$ PANI-DBSA exhibited a granular structure with a uniform size, and its morphology was similar to that of pure PANI. Also, the composites prepared by an APS oxidant exhibited a similar morphology. ${ }^{18}$

Figure 3 shows the FT-IR spectra of PANI-PS composites as a function of PANI-DBSA content (run

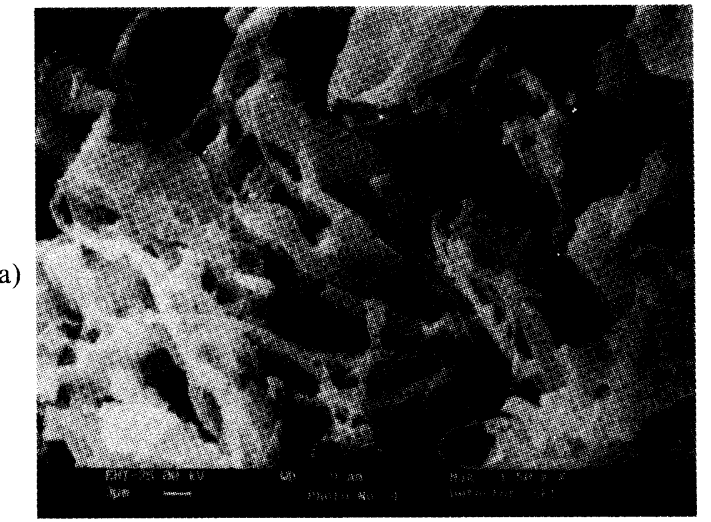

(b)

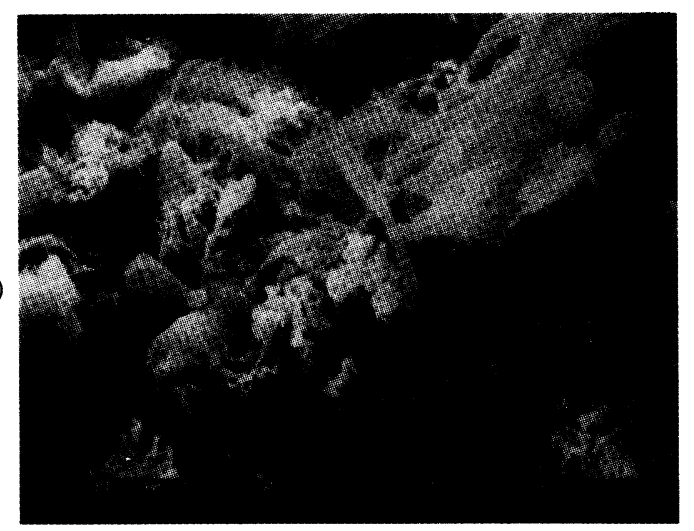

(c)

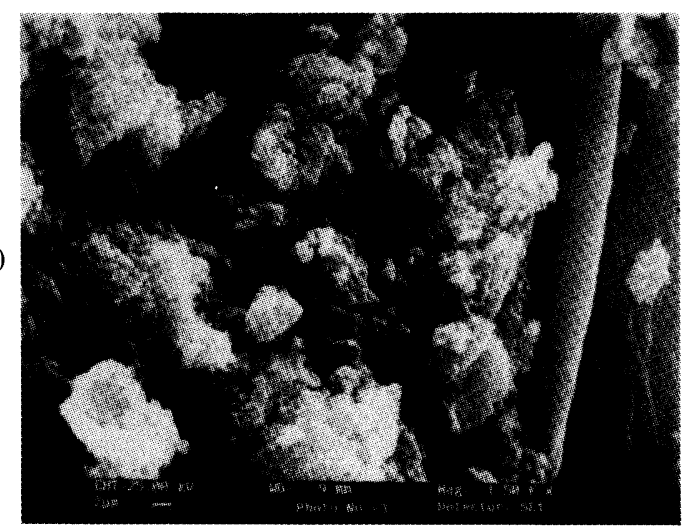

Figure 2. Scanning electron micrographs of PANI-PS composites prepared by a DDQ oxidant. (a) $3.8 \mathrm{wt} \%$ PANI-DBSA; (b) $10.9 \mathrm{wt} \%$; (c) $24 \mathrm{wt} \%$. 


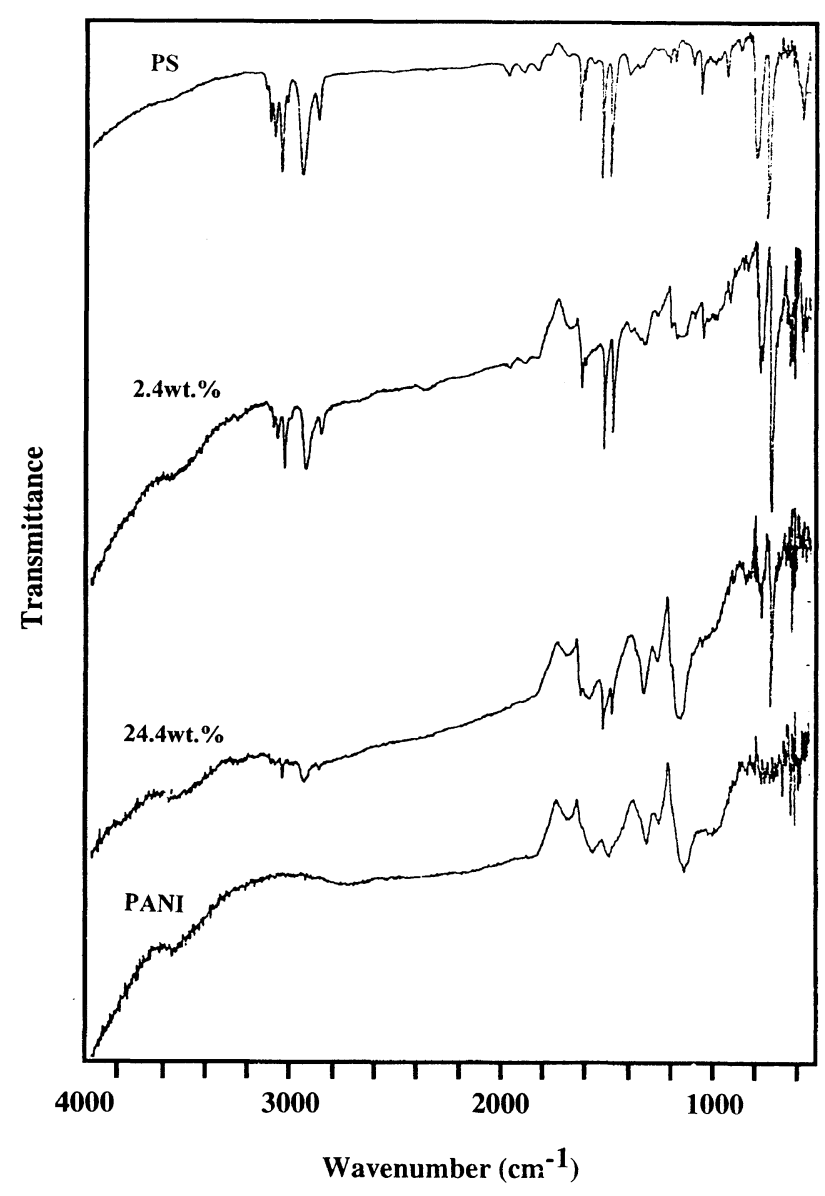

Figure 3. FT-IR spectra of PANI-PS composites.

No. 2, 9). As the content of conductive component increases, the intensity of absorption peaks assigned to PS at $3027,2920,1452$, and $697 \mathrm{~cm}^{-1}$ decreased, and the absorption peaks characteristic to PANI-DBSA complex, e.g., $\mathrm{N}-\mathrm{H}$ stretching vibration at $3541 \mathrm{~cm}^{-1}$, the deformation of benzene and quinone ring at 1564 and $1475 \mathrm{~cm}^{-1}, \mathrm{C}-\mathrm{N}$ stretching vibration at $1303 \mathrm{~cm}^{-1}$, and doping band at $1120-1002 \mathrm{~cm}^{-1}$ appeared. Especially, the FT-IR spectrum of PANI-PS composite containing $24.4 \mathrm{wt} \%$ PANI-DBSA was similar to that of pure PANI. Thus, it is evident from the SEM and FT-IR results that the physical properties of the PANI-PS composite with a large amount of conductive component is analogous to those of pure PANI.

In general, the electrical conductivity of PANI is significantly deteriorated at the elevated temperature of more than $150^{\circ} \mathrm{C}$ under nitrogen or air atmosphere, which is reported to be mainly due to the elimination of dopant molecule as well as decomposition of polymer backbone. ${ }^{19,20}$ Relating to the thermal stability of conductivity in PANI-PS composite, it may be useful to examine that of pure PANIs doped with various dopants. In order to evaluate the conductive stability of the PANI, thermal aging was carried out at $180^{\circ} \mathrm{C}$ for $3 \mathrm{~h}$ under nitrogen or air atmosphere. Figure 4 shows the dependency of electrical conductivity of conventional PANI doped with $\mathrm{HCl}$ or $\mathrm{H}_{2} \mathrm{SO}_{4}$ on the thermal aging time under nitrogen or air atmosphere. The stability of conductivity in DBSA doped-PANI prepared by a APS or DDQ oxidant is shown in Figure 5. The electrical conductivity of PANI doped with a large molecule

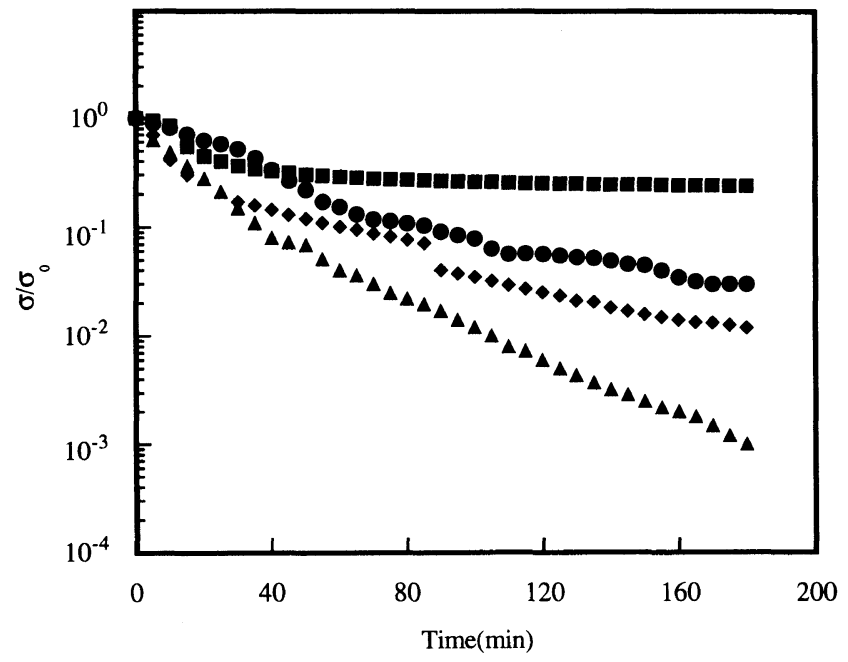

Figure 4. Changes in the electrical conductivity of doped PANI prepared by a APS oxidant during exposure to nitrogen $\left(\square, \mathrm{H}_{2} \mathrm{SO}_{4}\right.$; , $\mathrm{HCl})$ or air $\left(\bullet, \mathrm{H}_{2} \mathrm{SO}_{4} ; \Delta, \mathrm{HCl}\right)$ at $180^{\circ} \mathrm{C}$.

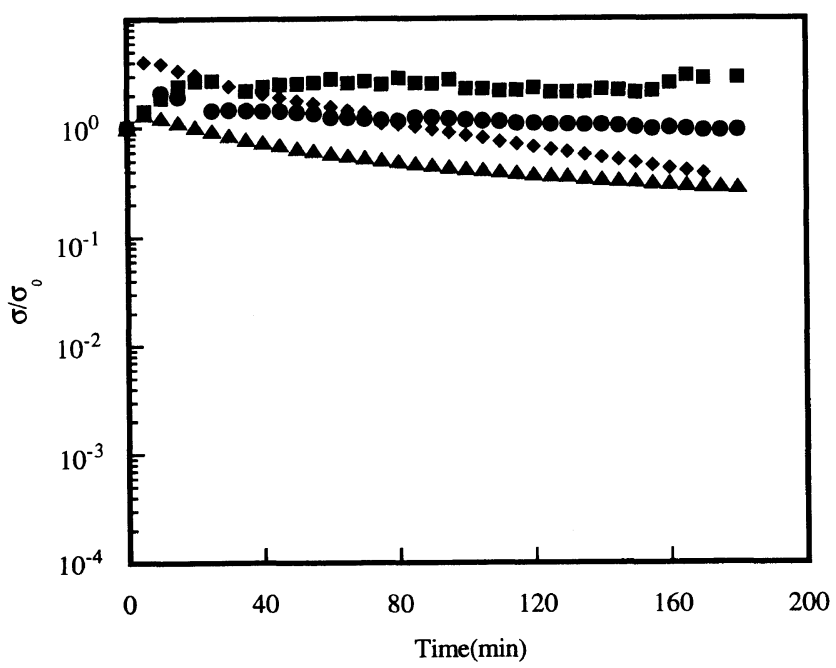

Figure 5. Changes in the electrical conductivity of PANIs doped with DBSA during exposure to nitrogen or air at $180^{\circ} \mathrm{C}$. $\square$, DDQ system, nitrogen; - , APS system, nitrogen; $\bullet$, DDQ system, air; $\boldsymbol{\Delta}$, APS system, air.

organic protonic acid such as DBSA was more stable than that of the conventional PANI. Based on our combined studies, the conductive stability of these four different classes of doped-PANIs is ranked as follows: PANI-DBSA (DDQ oxidant system) $>$ PANI-DBSA (APS oxidant system) $>$ PANI- $\mathrm{H}_{2} \mathrm{SO}_{4}>\mathrm{PANI}-\mathrm{HCl}$. The reasons for the observed propensity may be manifold, but one definite possibility appears to stem from the fact that it is difficult to eliminate dopant molecule by the thermal aging in case of the dopant consisted of a large molecule. Especially, the decrease in electrical conductivity of the DBSA doped-PANI prepared by a DDQ oxidant was less than that of PANI prepared by a APS oxidant. Here, it can be concluded that partial doping of a $\mathrm{H}_{2} \mathrm{SO}_{4}$ resulted from the oxidation of aniline by a APS oxidant during aniline polymerization. In thermal aging of the PANI at 150 or $230^{\circ} \mathrm{C}$, similar results were obtained. These results consistently indicate that the thermal stability of conductivity in PANI is enhanced by the presence of a dopant having large molecule. 


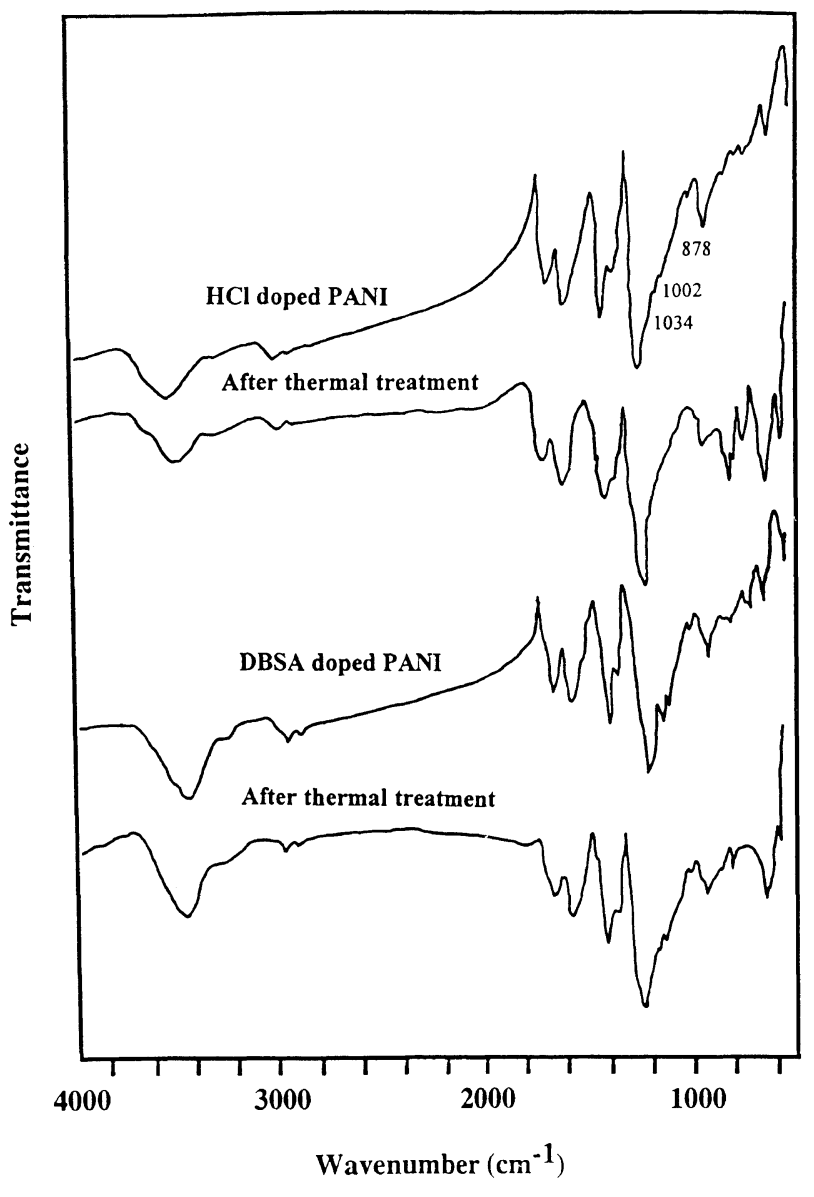

Figure 6. FT-IR spectra of PANI after thermal treatment.

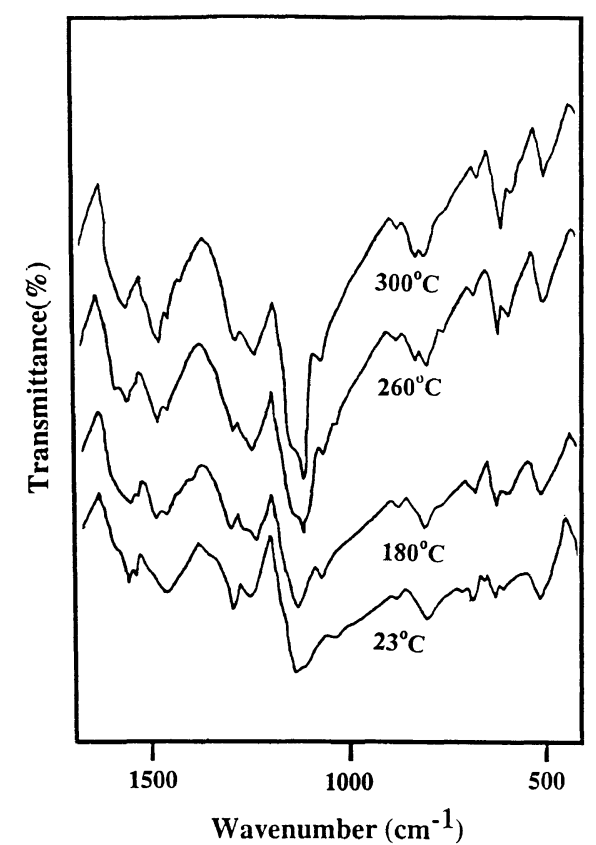

Figure 7. In-situ FT-IR spectra of PANI-DBSA complex during the thermal aging.

Figure 6 represents the FT-IR spectra of PANIs doped with $\mathrm{HCl}$ and DBSA before and after thermal aging at $180^{\circ} \mathrm{C}$ for $3 \mathrm{~h}$. After the thermal treatment, a PANI doped with $\mathrm{HCl}$ was completely dedoped, and the IR spectrum is seen to be essentially the same as that of emeraldine PANI base. On the other hand, the absorption peaks

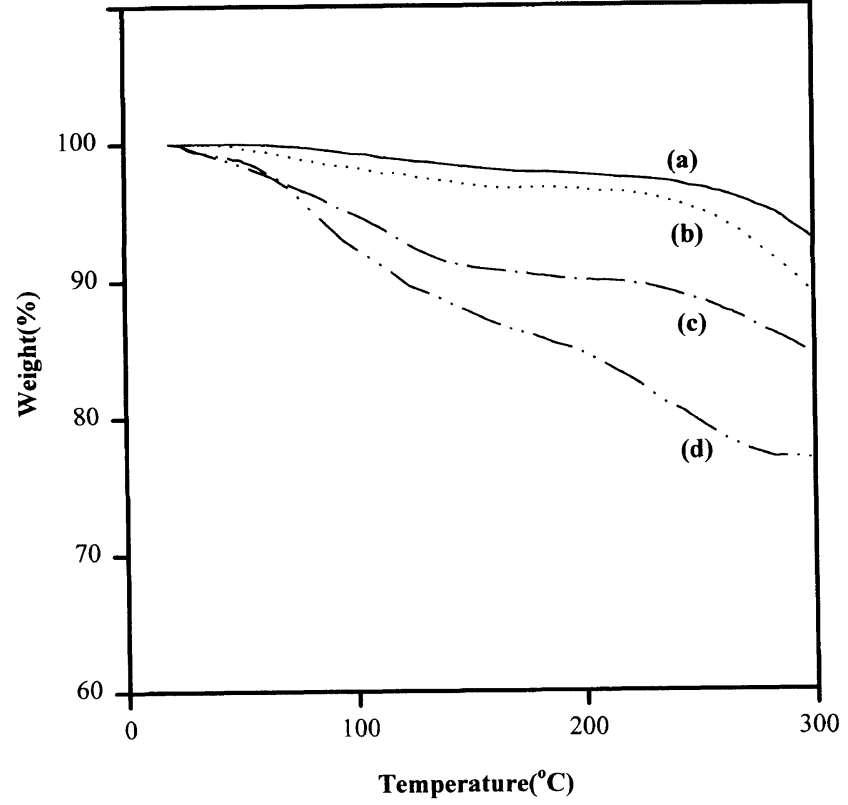

Figure 8. TGA curves of PANIs doped with (a) DBSA (DDQ system), (b) DBSA (APS system), (c) $\mathrm{H}_{2} \mathrm{SO}_{4}$, and (d) $\mathrm{HCl}$ in nitrogen.

assignable to the doping band at 1034, 1002, and $878 \mathrm{~cm}^{-1}$ remained after the thermal treatment in case of PANI doped with DBSA. This observation is in accord with the previous result, which shows that the PANI doped with DBSA is far more stable than conventional PANI-HCl complex. To investigate the change in the polymer structure by the thermal treatment, we measured in situ FT-IR of PANI-DBSA complex during the thermal aging from $30^{\circ} \mathrm{C}$ to $300^{\circ} \mathrm{C}$. The decomposition of PANI backbone or side reaction during heating took place over $230-250^{\circ} \mathrm{C}$ as shown in Figure 7 . The TGA curves of PANIs doped with various dopants are shown in Figure 8. The thermograms show a slow weight loss up to $230^{\circ} \mathrm{C}$ and a major loss above $230^{\circ} \mathrm{C}$. The slow weight loss below $230^{\circ} \mathrm{C}$ may be due to the removal of moisture as well as dopant molecule. The major weight loss above $230^{\circ} \mathrm{C}$ is ascribed to the structural decomposition of PANI backbone. This behavior is consistent with the result on the thermal stability obtained from the FT-IR measurement.

Lastly, it is worthy to note that the PANI-PS composite (run No. 8, $17.6 \mathrm{wt} \%$ PANI-DBSA) sheet meltprocessed at $150^{\circ} \mathrm{C}, 100$ psi condition exhibits relatively high level of electrical conductivity, $10^{-1}-10^{-2} \mathrm{~S}$ $\mathrm{cm}^{-1}$. This result demonstrates the feasibility of meltprocessing, in conducting form, the present PANI-PS composite.

\section{CONCLUSIONS}

It is shown that electrically conductive PANI-PS composite can be obtained by in-situ polymerization and blending in a xylene solution comprising DBSA, oxidant, aniline, and PS. The electrical conductivity of the prepared composite appeared to be increased as the content of PANI is increased and showed a relatively high value of $0.1 \mathrm{~S} \mathrm{~cm}^{-1}$ at only a small amount of conductive component as $12 \mathrm{wt} \%$. The PANI-PS composite was readily soluble in common organic solvents 
such as chloroform, NMP, and xylene. The change in electrical conductivity of pure PANI doped with various dopants upon thermal heating at $150-230^{\circ} \mathrm{C}$ suggested thermal stability to dopant size. Especially, the DBSA doped-PANI prepared by a DDQ oxidant exhibited the best stability in conductivity at the elevated temperatures. Finally, a novel class of polyblend having a truly unique combination of electrical properties was obtained, and the resulting PANI-PS composites can be melt processed or processed from solution blending to enable the fabrication of thin films or sheets while keeping stable conductivity.

Acknowledgments. This work was supported by a research grant from the Korea Science and Engineering Foundation (Proposal No. 951-1101-029-1).

\section{REFERENCES}

1. F. Trinidal, M. C. Montemayor, and E. Falas, J. Electrochem. Soc., 138, 3186 (1991).

2. D. C. Trivedi and S. K. Dhawan, J. Mater. Chem., 2, 1091 (1992).

3. T. Taka, Synth. Met., 41-43, 1177 (1991).

4. H. Nishino, G. Yu, A. J. Heeger, T. A. Chen, and R. D. Rieke,
Synth. Met., 68, 243 (1995)

5. G. Gustafsson, Y. Cao, G. M. Trevedi, F. Klavetter, N. Colaneri, and A. J. Heeger, Nature, 357, 447 (1992)

6. P. N. Bartlett, B. M. A. Patricia, and K. L. C. Sin, Sensors and Actuators, 19, 125 (1989).

7. S. Y. Oh, K. Akagi, H. Shirakawa, and K. Araya, Macromolecules, 26, 6023 (1993).

8. K. Akagi, H. Goto, Y. Kadokura, H. Shirakawa, S. Y. Oh, and K. Araya, Synth. Met., 69, 13 (1995).

9. L. H. Dao, M. Leclerc, J. Guay, and J. W. Chevalier, Synth. Met., 29, E377 (1989).

10. S. Li, Y. Cao, and Z. Xue, Synth. Met., 20, 141 (1987).

11. Y. Cao, P. Smith, and A. J. Heeger, Synth. Met., 48, 91 (1992).

12. E. Ruckenstein and S. Yang, Synth. Met., 53, 283 (1993).

13. R. Zallen, "The physics of Amorphous solids", Wiley, New York, N.Y., 1983.

14. E. C. Cooper and B. Vincent, J. Phys. D: Appl. Phys., 22, 1580 (1989).

15. C. Y. Yoon, M. Reghu, D. Moses, Y. Cao, and A. J. Heeger, Synth. Met., 69, 91 (1995).

16. C. Y. Yang, Y. Cao, P. Smith, and A. J. Heeger, Synth. Met., 53, 293 (1993).

17. J. L. Moigne and A. Hilberer, Macromol. Chem., 192, 515(1991).

18. S. Y. Oh and H. C. Koh, J. Korean Ind. \& Eng. Chem., 6, 1108 (1995).

19. J. Yue, A. J. Epstein, Z. Zhong, and P. K. Gallagher, Synth. Met., 41-43, 765 (1991).

20. Y. Wang and M. F. Rubner, synth. Met., 47, 255 (1992). 